changing in many lower-income contexts. As increasing numbers of young people complete primary and secondary education - and as the youth population surges across the globe-tertiary education is positioned as being crucial for economic development. This review supports such assertions. However, it also highlights the diverse noneconomic benefits that should also be acknowledged and considered in the development of policy.

\section{World Economies and the Distribution of International Branch Campuses}

\section{Li Zhang, Kevin Kinser, and Yunyu ShI}

Li Zhang is a doctoral student in the Department of Educational Administration and Policy Studies and research assistant for the CrossBorder Education Research Team (C-BERT) at the State University of New York at Albany. E-mail: Izhang6@albany.edu. Kevin Kinser is associate professor and chair of the Department of Educational Administration and Policy Studies and co-director of C-BERT at the State University of New York at Albany. E-mail: kkinser@albany.edu. Yunyu (Stephanie) Shi is a visiting scholar in the Department of Educational Administration and Policy Studies and researcher for C-BERT at State University of New York at Albany. E-mail: stephaniesyy@hotmail.com.

The international branch campus has become a sym1 bol of higher education internationalization in recent years. Perhaps because the dominant exporting countries have been the United Kingdom, the United States, and Australia, many people assume that the higher education export flows from developed countries to developing countries, in a West-to-East fashion. However, using data from the Cross-Border Education Research Team (C-BERT) at the University at Albany, State University of New York alongside an economic framework provided by the World Economic Forum, we look at the distribution of international branch campuses around the world. There are distinct patterns between host and home countries and the interests countries have for establishing international branch campuses are connected to economic competitiveness.

\section{World EConomic Forum's Global Competitive Index}

Since its development in 2004, the World Economic Forum's global competitive index has been widely used to measure and compare countries' productivity and economic prosperity. It uses I2 competitive index measures, to cat- egorize countries into three types of economies. The index measures are designed to describe economic competitiveness in a country more accurately than the controversial categories of developing or emerging countries.

The first four pillars-institutions, infrastructure, macroeconomic environment, and health and primary education-create factor-driven economies. Fifty-eight countries belong to this category where they use low wages and natural resources for competitive advantage. A second category of 53 efficiency-driven economies are determined by six different pillars: higher education and training, good-market efficiency, labor-market efficiency, financial market efficiency, technology readiness, and market size. These countries compete through the development of a skilled workforce and increased product quality. Finally, innovation-driven economies rely on the two pillars of business sophistication and innovation, to boost their economic development. Thirty-six countries are innovation-driven economies that have advanced production processes and the capacity to create unique products.

Since higher education competitiveness is one indicator of a country's economic competitiveness, the former usually reflects the latter, but that is not always the case. For instance, Bahrain is listed as an innovation-driven economy, but its higher education competitiveness is ranked 53rd among the I47 countries. Barbados, Estonia, Lithuania, Costa Rica, Poland, Chile, and Latvia are efficiency-driven economies, but their higher education competitiveness is on par with that of innovation-driven economies. In the same vein, Saudi Arabia, Brunei, Sri Lanka, Philippines, Venezuela, and Armenia are factor-driven economies with more competitive higher education than many efficiencydriven economies.

\section{International Branch Campuses}

C-BERT has identified 20I international branch campuses in operation worldwide. Using the World Economic Forum framework, we grouped these campuses into 9 categories based on the classification of the home and host countries, as either factor-, efficiency-, or innovation-driven economies.

There are a total of 12 international branch campuses established by 5 factor-driven economies-including India, Iran, Pakistan, Philippines, and Venezuela. All the factordriven economies establish their branch campuses in innovation-driven economies, rather than factor-driven or efficiency-driven economies. United Arab Emirates (UAE) is the biggest importer, hosting eight of such international branch campuses, while India becomes the biggest factordriven exporting economy, having 9 branch campuses worldwide, mainly in UAE. 
Seven efficiency-driven economies have opened a total of 2I international branch campuses. These countries include China, Malaysia, Russia, Chile, Mexico, Lebanon, and Estonia. Unlike the factor-driven economies, such campuses from efficiency-driven economies are roughly evenly distributed among the three types of economies: 7 branch campuses are established in factor-driven economies, 8 in efficiency-driven economies, and 6 in innovation-driven economies. It is noteworthy that these efficiency-driven economies tend to establish the campuses in their neighboring countries or within the same region. For example, Russia has branch campuses in Armenia, Ukraine, Uzbekistan, Azerbaijan, Kazakhstan, and Tajikistan, which were

\section{Since its development in 2004, the World Economic Forum's global com- petitive index has been widely used to measure and compare countries' pro- ductivity and economic prosperity.}

part of the former Soviet Union. When neighboring countries have a less-competitive higher education sector and share similar culture and language, they are less risky as hosts compared to more far-flung locations.

The majority of international branch campuses, however, are established by innovation-driven economies: I68 out of a total of 201 such campuses worldwide. The innovation driven economies of the United States, United Kingdom, France, and Australia are the biggest exporters of higher education. United States alone has 77 branch campuses worldwide, more than the number established by the United Kingdom, France, and Australia combined. Only II of these international branch campuses are established in factor-driven economies, while 66 are established in efficiency-driven economies and 9I are established among innovation-driven economies. Among these branch campuses worldwide, export from innovation economy to innovation economy is therefore the most common form of them.

The United Arab Emirates, Singapore, and Qatar are the major innovation economies that host international branch campuses. These three countries aspire to become regional hubs by providing preferential policies for foreign institutions. China and Malaysia are the major efficiencydriven economies that import higher education from innovation countries. The Chinese government encourages the "bring in" of foreign education in order to improve its own higher education quality and plans to host another 5 to Io international branch campuses in the following decade. Malaysia aspires to become a regional hub by inviting foreign institutions to open branch campuses in hubs at Iskandar and Kuala Lumpur Education City.

\section{CONCLUSION}

Our focus here is not on specific countries and their interests in the international branch campuses phenomenon, but the patterns suggested by this worldwide distribution under the World Economic Forum framework. The analysis presents a picture of institutional mobility, different from an outdated model that presumes flows are predominately from developed to developing countries. The majority of international branch campuses have been established between innovation-driven economies, as well as some factor-driven and efficiency-driven economies extending their presence into innovation-driven economies. It is important to understand the myriad of reasons why emerging economies welcome such campuses, and how this might reflect national development agendas. Unmet demand for education and an emphasis on building a competitive workforce are often combined with regulatory incentives that encourage foreign investment in the direct provision of education. The multinational university may reflect the innovation economy's dominant entrepreneurial response to this scenario.

\section{International Visiting Scholars: Brain-Circulation and Internationalization}

\section{YUкIKo SHIm m I}

Yukiko Shimmi is an assistant professor at the Graduate School of Law at Hitotsubashi University, Tokyo, Japan. She recently received her doctorate from Boston College. Her doctoral dissertation is focused on the experiences of Japanese visiting scholars in the United States. E-mail: yshimmi@gmail.com.

Tnternational visiting scholars are scientists and profes1 sors who attend universities in other countries to engage temporarily in research or teaching, while also maintaining their affiliation and position at their home universities and returning after their visiting period ends. They usually have doctoral degrees or are professionally trained. Unlike international students, visiting scholars come and leave at 